\title{
Expressive language in 4 to 8 years old children with Down syndrome and typical development: Evidence from the Greek language
}

\author{
Georgia Andreou, Dimitra Katsarou \\ Department of Special Education, University of Thessaly, Greece \\ https://doi.org/10.36505/ExLing-2015/06/0001/000238
}

\begin{abstract}
In this paper we report the results of an experiment we carried out in order to investigate expressive language in Down Syndrome (DS). Research has shown that during pre-school and school years, children with DS use expressive skills processes and sound patterns that are similar to those used by typically developing children. However, they eliminate these processes at a slower rate. In view of the above we conducted an experiment so as to investigate expressive language skills in forty five children with DS and forty five children with typical development in order to compare and contrast their language development. Our results showed that children with DS present more expressive language impairments in the Greek language than their typically developing counterparts.
\end{abstract}

Key words: Down Syndrome, expressive language, Greek

\section{Introduction}

Down Syndrome is caused by trisomy of all parts of chromosome 21 and is the most common genetic cause of significant intellectual disability, occurring at approximately 1 in 700 to 1 in 800 live births (Centers for Disease Control and Prevention 2006). Delayed and disordered speech and language development are among the hallmark features of Down Syndrome (Abbedduto and Hagerman 1997). These delays and disorders are usually apparent early in development, but delays in communication and slow rate of language development usually do not cause parental concern, since Down Syndrome can be diagnosed before or at birth (Roberts et al. 2007). Further motor impairments that generally affect the development of speech, including low muscle tone in the tongue, lips and cheeks, result in less firm and precise production of speech sounds (Kumin et al. 1996). As a result, children with Down Syndrome have difficulty in speech production and intelligibility stemming, at least in part, from difficulty with muscle timing and coordination (Iverson et al. 2003). More specifically, previous research in the expressive domain of language between children with Down Syndrome and children with typical development has proven that poor phonological skills could also account for expressive language impairment in Down Syndrome. Numerous studies associate a deficit in expressive skills with DS (Jarrold et al. 2000; Seung and Chapman, 2000). Some research point out that the problem appears to be

ExLing 2015: Proceedings of 6th Tutorial and Research Workshop on Experimental Linguistics, 26-27 June 2015, Athens, Greece 
independent of hearing impairment or speechmotor deficits (Jarrold et al. 2002; Seung and Chapman, 2000). Nonetheless although some evidence points to lack of articulatory rehearsal as its possible cause (Hulme and Mackenzie, 1992). Some other researchers report that individuals with Down Syndrome might find non-word repetition a particularly difficult task. Tests with words and nonword tasks involve auditory presentation of the non-word stimuli, and spoken repetition responses. Performance is therefore likely to be affected by both hearing ability and speech production skills (Edwards and Lahey, 1998).

\section{Experimental Procedure}

We used a standardized test of expressive language (Tzouriadou et al. 2008) which examines articulation and oral vocabulary. Articulation was examined in two different ways. In the first task, consisting of 13 items, we asked the children to complete a sentence by showing them a picture, such as / ta pedia grafun pano sto...../ (children write on the...) and the children had to answer correctly /thranio/ (desk). In the second task, consisting of 16 items, we asked them to complete the sentence correctly, for example / I Maria ine gineka. O

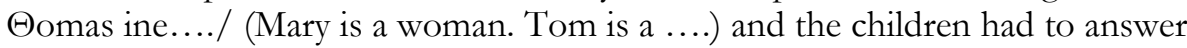
correctly / andras / (man).

Oral vocabulary was examined, also, in two different ways. In the first task consisting of 14 items, we asked the children to find a word that starts with a specific combination of vowels and consonants and means something. For example I want you to tell me a person in the family that is a man and starts with / ba/ and the child had to answer correctly /babas/ (dad). In the second task, consisting of 15 items, we asked them to tell us the definition of a word, for example / ti ine skilos/ (what is a dog?) and the child had to answer /ena zoo pu gavgizi/ (an animal that barks).

\section{Subjects}

45 children with Down Syndrome, mild mental retardation and Greek origin and 45 children with typical development were examined in the two tasks. Their age varied from 4 years to 8 years old and had no other language impairments or health problems that could affect the results of this research.

\section{Results}

For the data analysis we used SPSS version 20.0. A two way analysis of variance (2-way ANOVA) was conducted to determine the effects of age and experimental group on factor expressive language. The results indicated a significant main effect for the group $\left(F_{7,74}=3.89, p<.05, \eta^{2}=0.26\right)$, a significant main effect for age group $\left(\mathrm{F}_{7,74}=4.29, p<.05 \eta^{2}=0.28\right)$ and a significant interaction between the study group and age group. The age group differences 
for Down syndrome were noted between children aged 48-53 months and 9095 months $(M D=1.50, p<.05)$. However in the control group the corresponding differences were noted between children aged 48-53 months and 60-65 months $(M D=2.11, p<.05)$.

\section{Discussion}

Our findings confirm the continuous problems children with Down Syndrome seem to experience in the expressive domain of language. Difficulties in the expressive language seem to combine with difficulties in articulation, proving that motorspeech deficits can be a serious problem in language development. Children with typical development scored higher in all categories than children with Down Syndrome, an outcome that was expected and is in line with previous research (Yoder and Warren 2004). Expressive language abilities in children with typical development seem to develop in normal age, whereas children with Down Syndrome seem to experience an unusual rate of language development. Children with Down Syndrome aged 48-53 months old seem to develop their expressive language abilities in higher rate than those aged 60-65 months old, proving that expressive language abilities decline as those children enter their school age. This may be explained by the requirements of the test and by the difficulties this specific population experience throughout everyday life at school.

Moreover, the findings of this research show the importance of early language intervention as well as the need for special education to focus on language skills.

However, these results must be treated with caution since it was only a small-scale investigation and children with DS who consisted our sample were not followed longitudinally. Therefore, more longitudinal research studies on Down Syndrome expressive language are needed with large samples which will be followed from childhood right through adolescence and adulthood.

\section{References}

Abbeduto, L. and Hagerman, R. J. 1998. Language and communication in Fragile X syndrome. Mental Retardation and Developmental Disabilities Research Reviews 3, 313-322.

Centers for Disease Control and Prevention 2006. Improved national prevalence estimates for 18 selected major birth defects-United States, 19992001.Morbidity and Mortality Weekly Report 54, 1301-1305.

Edwards, J. and Lahey, M. 1998. Non word repetitions of children with specific language impairment: Exploration of some explanations for their inaccuracies. Applied Linguistics 19, 279-309.

Jarrold, C. Baddeley, A. D. and Hewes, A. K. 2000. Verbal short term memory deficits in Down Syndrome: A consequence of problems in rehearsal. Journal of Child Psychology and Psychiatry and Allied Disciplines 41, 233-244. 
Jarrold, C. Baddeley, A. D. and Phillips C. E. 2002. Verbal short memory of Down Syndrome: A problem of memory, audition or speech? Journal of Speech, Language and Hearing Research 45, 531-544.

Hulme, C. and Mackenzie, S. 1992. Working memory and severe learning difficulties. Hillsdale, Lawrence Earlbaum Associates Inc.

Iverson, M., Longobardi, E. and Caselli, C. 2003. The relationship between gesturesand words in children with Down Syndrome and typically developing in the early stages of communicative development. International Journal of Language and Communication Disorders 38, 179-197.

Kumin, L., Goodman, M. and Councill, C. 1996. Comprehension speech and language intervention for children with Down Syndrome. Down Syndrome Quarterly 1, 1-8.

Roberts, J.E., Price, J.R. and Malkin, C. 2007. Language and communication de velopment in Down Syndrome. Mental Retardation and Developmental Disabilities Research Reviews 13, 26-35.

Seung, H. K. and Chapman, R.S. 2000. Digit span in individuals with Down syn drome and typically developing children: Temporal aspects. Journal of Speech, Language, and Hearing Research 43, 609-620.

Tzouriadou, M., Singolitou, E., Anagnostopoulou, E. and Vakola, I. 2008. Psychometric criterion of Language Adequacy (L-a-T-o). Thessaloniki, Aristotle University of Thessaloniki and Ministry of Education.

Yoder, J. and Warren, F. 2004. Early predictors of language in children with and without Down Syndrome. American Journal of Mental Retardation 109, 285-300. 